\title{
Contribuições ao estudo dos principais modelos de desdobramento da teoria de resposta ao item com aplicações em psicologia
}

\author{
Marília Gabriela Rocha*, Caio Lucidius Naberezny Azevedo.
}

\begin{abstract}
Resumo
É de grande interesse na área da Psicometria a utilização de modelos de variáveis latentes, os quais permitem fazer inferências sobre variáveis não observáveis (latentes) de interesse. O presente projeto tem por objetivo estudar os principais modelos de desdobramento paramétricos e unidimensionais da Teoria de Resposta ao Item (TRI), provendo uma revisão metodológica, discutindo aspectos como interpretação, aplicabilidade e estimação. Além disso, revisaremos os arcabouços computacionais disponíveis, realizando implementações adicionais, dessa natureza, se necessário, através dos métodos marginais-perfilados frequentistas/bayesianos. Serão utilizados os pacotes mirt e GGUM da linguagem R. Também será considerada uma aplicação na área da psicologia, através da análise da versão brasileira da Observer Alexithymia Scale (OAS), considerando a adequabilidade que os modelos de desdobramento têm em relação a instrumentos de medida relacionados à atitude.
\end{abstract}

\section{Palavras-chave:}

TRI, GGUM, psicologia.

\section{Introdução}

Os modelos da TRI, segundo a natureza do traço latente, podem ser cumulativos ou de desdobramento. Apesar de serem os mais difundidos, os modelos cumulativos nem sempre são os mais apropriados. Particularmente, quando as probabilidades de se obter um escore (no item) maior não aumentam com o aumento no valor do traço latente, mas sim com a proximidade do valor do traço latente em relação ao posicionamento do item na escala, os modelos de desdobramento são preferíveis. $O$ modelo de desdobramento gradual generalizado (GGUM) será estudado detalhadamente, dada sua importância, principalmente na análise de questionários relacionados à aspectos psicológicos. Como há poucos trabalhos na literatura em Língua Portuguesa sobre o tema, é de grande relevância um estudo aprofundado sobre essa classe de modelos. Visando facilitar sua aplicação, também é pertinente um estudo sobre o desenvolvimento computacional dos modelos por meio de pacotes já existentes, como o mirt (CHALMERS, 2012) e GGUM (TENDEIRO, 2018), disponíveis na linguagem R. Será verificada a viabilidade de utilização do modelo GGUM para análise da versão brasileira da Observer Alexithymia Scale (OAS) (CARNEIRO et al., 2008).

\section{Resultados e Discussão}

Muitas pesquisas têm mostrado que respostas binárias ou graduais para itens de atitude resultam de um processo de ponto ideal, no qual o respondente concorda com uma declaração de atitude à medida em que ela corresponde à sua opinião (ROBERTS, 1996). Isto, por sua vez, sugere que um modelo de proximidade seria 0 ideal para analisar respostas na escala concordodiscordo e, sendo assim, o foco deste trabalho foi estudar os modelos de desdobramento, especialmente 0 GGUM, devido à sua generalidade.

Foi realizado um estudo teórico do modelo, das estimações dos parâmetros dos itens por máxima verossimilhança marginal, via algoritmo pseudo EM, e dos indivíduos, por meio do método de esperança à posteriori (EAP). Também se estudou a função de informação dos itens e dos testes e ferramentas de verificação da qualidade de ajuste do modelo (gráfico dos escores esperados e observados dos itens e cálculo do $\chi^{2}$ ajustado à razão dos graus de liberdade, introduzido por DRASGOW et al., 1995). Além disso, o modelo foi avaliado via dados simulados, por meio das funções GGUM e mirt em linguagem R. Verificou-se como se comportam em relação à qualidade das estimativas e tempo de processamento, considerando também as possibilidades de visualização disponíveis em cada pacote e ferramentas para verificação da qualidade do ajuste do modelo.

Em comparação ao GGUM, apesar de possibilitar maiores opções para análise do modelo e os resultados apresentarem grande semelhança em grande parte das estimações, o mirt apresentou, em algumas situações, estimações bem ruins. Também foi feita uma análise gráfica minuciosa de como o modelo se comporta de acordo com os parâmetros de discriminação e dificuldade dos itens e seus limiares, tanto em relação às curvas de respostas características quanto em relação às funções de informação dos itens.

\section{Conclusões}

Foi possível conhecer mais detalhadamente os modelos da TRI, suas utilizações dentro da área Psicométrica, suas adequabilidades a diferentes casos e recursos computacionais disponíveis para estimação de seus parâmetros, além de outras funcionalidades que os pacotes mirt e GGUM em linguagem $R$ oferecem. Para setembro, espera-se ter uma aplicação do GGUM para os dados de resposta do questionário OAS.

\section{Agradecimentos}

Fundação de Amparo à Pesquisa do Estado de São Paulo.

${ }^{1}$ CHALMERS, M. P. Package 'mirt'. Citeseer, 2012.

2 TENDEIRO, N. J. Package 'GGUM', 2018.

3 CARNEIRO, B. V. B. V. et al. Propriedades psicométricas da OASObserver Alexithymia Scale: versão brasileira. Pontifícia Universidade Católica de Campinas, 2008.

4 ROBERTS, J. S. Item response theory approaches to attitude measurement. ProQuest Information \& Learning, 1996.

5 DRASGOW, F. et al. Fitting polytomous item response theory models to multiple-choice tests. Applied Psychological Measurement, Sage Publications Sage CA: Thousand Oaks, 1995. 